\title{
THE DESIRABILITY OF AN INQUIRY INTO THE EFFECT OF HOSPITAL ISOLATION OF SCARLET FEVER, AND THE FORM AN INQUIRY SHOULD TAKE.*
}

\author{
BX JAMES WHEATLEY, M.D. (L $\mathrm{L}_{\mathrm{ND}}$.),
} Medical Officer of Health for the County of Salop.

IT is not my wish to open a discussion upon the effect of hospital isolation on scarlet fever incidence or mortality, but simply upon the desirability of an investigation of an authoritative and thorough bind. I shall not bring forward any statistics bearing upon this question, but must assume that each member has carefully considered for himself the arguments that have been advanced for and against the isolation of scarlet fever in hospitals.

The pioneers of hospital isolation had, undoubtedly, good grounds for the course they took. Stated briefly, the principle underlying our action against the spread of infectious disease is to destroy infection before it can come into contact with susceptible material. For this purpose notification, isolation, quarantine of contacts, and disinfection are practised. Without isolation these measures necessarily fall to the ground. Isolation at the homes of the poor was found to be very imperfect, and consequently hospitals were provided.

It may, I think, be assumed that any course of action which systematically prevents infectious matter from coming into contact with susceptible persons will, if no fresh conditions are created, lessen. the particular infectious disease, except where the disease is limited only by the exhaustion of the susceptible material. Those who say that isolation of scarlet fever in hospitals is practically without any beneficial effect, contend:-

(1). That the most infectious period is generally over before the patient is removed to hospital.

(2). That hospital infection counterbalances the restriction of spread due to isolation in hospital.

(3). That isolation of scarlet fever in hospitals having been practised for thirty years, it should be possible to prove its benefit. by accomplished facts.

Until quite recently no inquiry seems to have been directed towards estimating the effect of hospital isolation. In 1897 Dr. J. T. Wilson incidentally threw some light upon this question in a paper entitled

* Read at a meeting of the West of England and South Wales Branch of the Society of Medical Officers of Health. 
"A Contribution to the Natural History of Scarlet Fever." His conclusions were, so far as they affect the present subject, that the great decline in the mortality of scarlet fever between 1870 and 1890 was not due to special preventive measures, and that although by isolation the prevalence of the disease has no doubt been diminished, and by proper hospital treatment the fatality lessened, yet the effect of these preventive measures (very local in their application) may almost be left out of account in considering the cause of the general reduction of scarlet fever mortality which has occurred throughout Great Britain. With this conclusion I think we all agree.

In February, 1901, Dr. Millard read before the Society a paper containing the result of a very considerable statistical investigation into this subject. His conclusions were :-

(1). That hospital isolation appears to have failed to materially reduce the prevalence or fatality of scarlet fever.

(2). That the fatality of scarlet fever has fallen most in those large towns that have not practised hospital isolation.

This paper has been very severely criticised. The statistics have been shown to be in many ways incomplete, and to some extent perhaps misleading. Comparisons were no doubt made between towns that were not wholly comparable, and periods were sometimes selected that did not lend themselves to comparison. It will, however, always be possible to raise similar objections to statistics which are affected simultaneously by several different agencies. To my mind the only effective criticism of this paper will be a thorough and exhaustive statistical inquiry.

The difficulties in the way of making an investigation into this subject are principally due to the fact that isolation is only one of many factors influencing the spread of infectious disease. There are the other measures commonly used for controlling infectious disease, differing in the thoroughness with which they are employed in different districts. There are differences in social conditions, habits, housing conditions, and differences in exposure to infection. There are, in all probability, conditions favourable to the spread of the disease of which we are ignorant, but which may have a very considerable influence on its distribution. There are difficulties introduced by the fact that large outbreaks of scarlet fever alternate with periods of comparative quiescence, making it necessary to use the greatest caution in comparing one locality with another, or periods of time in the same locality. Are we to give way in the face of these difficulties, and say that it is impossible to arrive at any satisfactory conclusion by means of statistics? Rather, I think we should recognize the difficulties, and deal with the question in a thorough 
and comprehensive manner. If hospital isolation has had any considerable effect, it seems very unlikely that this effect will not show itself in carefully compiled statistics with sufficient clearness to satisfy an unbiassed mind. If, on the other hand, it is shown that general statistics are no use for this purpose, that in itself will be a great gain.

It has been frequently said that each Medical Officer of Health must make his own investigations. This must necessarily be so for his own town; no one else is in a position to make them. Even here, however, a Committee of Inquiry appointed by this Society could be of great help. The result of the examination of many annual reports of towns where hospital isolation is practised, has impressed me with the fact that much valuable material which would throw light on this question is being lost. In some of the reports there are certainly very thorough investigations, but these, not being conducted on uniform plans, are rarely comparable.

Dr. Niven, from a very careful and thorough analysis of the cases of scarlet fever in Manchester in 1901, came to the following conclusions:-

(1). That hospital isolation had reduced the number of cases of scarlet fever in Manchester, but that the reduction was not so great as could be desired.

(2). That the chief agencies against the utility of the hospital were the return cases and the overlooked and doubtful cases.

(3). That by adequate hospital administration the return cases may probably be reduced so as to make them almost inoperative for harm.

This line of investigation is possibly the most promising, but, unfortunately, it cannot be considered conclusive until return cases have ceased to occur. To my mind it is a perfectly sound argument that the recognised return cases may only represent a small portion of the cases that are infected from hospitals. The household to which the patient returns has already been exposed to infection, and one or more of its members have already been attacked. It is not then so promising a field for the spread of the disease as an ordinary household. On the other hand, the patient, on returning from the hospital, mixes freely with other children, and returns to school within a short period.

I think, therefore, it is extremely probable that the hospital is responsible for many more cases than are represented by "return cases." For this reason, if for no other, it is necessary to supplement the facts obtained from a comparison of home cases with hospital cases in any given town, with a study of the incidence and mortality in various towns having different conditions of isolation. Here we 
are on very dangerous ground, where every step requires the closest investigation. If it is to carry any weight, such an investigation must be made by a responsible and capable body. Personally, I believe that an inquiry will prove that hospital isolation in scarlet fever, properly conducted, will diminish both the incidence and fatality of the disease, but it may mean revolutionising our methods. It is a question of the decrease on the one hand by isolation, and the increase on the other by hospital infection.

As far as I am aware, the only objection to an investigation that has been raised is that it may shake the confidence of the public in the principle of isolation. This objection may have some force if used against bringing before the public the result of partly-thoughtout and immature investigations, but it cannot have any force against such an inquiry as I am proposing. I deprecate myself even the general discussion that is going on in our medical papers, because, while it does not add to our knowledge, it intensifies the feeling that has already been introduced into this discussion, much to its detriment.

The arguments in favour of the Society appointing a Committee of Investigation may be briefly summarized:-

(1). It is certainly our duty to throw as much light on this subject as possible. Yet, although hospital isolation of scarlet fever has been extensively practised during the last twenty years, no systematic inquiries have yet been made with the object of estimating the results obtained.

(2). An inquiry is the more urgent because a doubt has been cast upon the advantages of hospital isolation, and this has been supported by figures which, although incomplete in many respects, and possibly misleading in others, have not been refuted by a fuller and more systematic investigation.

(3). Considerable feeling has been excited, obscuring the issue and adding greatly to the difficulty of solving the various problems, except by an official investigation.

(4). The difficulties that have been pointed out are so great that anything but the fullest inquiry by the most competent persons is likely to be a failure.

(5). The Committee of Inquiry might draw up a scheme for the guidance of Medical Officers of Health in reporting on the result of hospital isolation in their districts. This can only be done by some authoritative body, and is in itself sufficient justification for the formation of such a body. A scheme of this description would not only save the Medical Officer of Health much trouble, but would make his reports of much greater value, and would enable them to be compared with others and a summary of the whole compiled. 
(6). An inquiry might throw considerable light upon the subject of return cases, and particularly the amount of scarlet fever that these are responsible for; also upon the suggested increased virulence of hospital-infected cases, the infectious character of various complieations, and other matters connected with the isolation of scarlet fever.

(7). If an investigation is desirable, it is certainly better that we should make it ourselves, than that it should be made for us.

On these grounds I propose the following resolution: "That in the opinion of this branch an investigation into the various problems associated with the isolation of scarlet fever in hospitals is desirable, and that the investigation should be undertaken by a Committee of this Society specially formed for that purpose."

Dr. Chantemesse has been appointed Inspector-General of Sanitation in Paris, in succession to the late Professor Proust. Dr. Chantemesse, it need hardly be added, is a bacteriologist of note, who has made a special study of cholera and tyhpoid fever.

Epidemic Sore Throat communicated by Milk from Cows suffering from Suppurative Mammitis.-Dr. R. W. C. Pierce, Medical Officer of Health for Guildford and Woking, has recently reported upon an outbreak in October last of sore throats, at first thought to be diphtheritic, but eventually found to be associated with streptococei and staphylococci. The cases varied in severity, some being slight attacks of follicular tonsillitis, others of quinsy with considerable amount of constitutional disturbance, and a few proved fatal. Several cases developed erysipelas of the face and neck. Information was obtained of ninety-eight infected houses, and seventy-six of these were supplied direct by two milkmen obtaining their milk from a common source. The farmer was found to have suffered from a quinsy sore throat about the middle of September, and four cows were affected with suppurative mammitis, yielding pinkish milk. Bacteriological examination showed the presence of similar organisms to those found in the throats of persons affected. The milk from two of the cows contained a large quantity of pus. It was the custom to send the afternoon's milk to Woking in the evening, and it was kept there overnight for distribution next morning. This keeping of the milk would contribute enormously to the growth of the organisms concerned, so that every drop would be thoroughly impregnated with the infection before it reached the consumer. It is noteworthy that external examination of the diseased udders gave no indication of the conditions such as would be yielded by tuberculous udders. It was only by the actual milking of the cows that the inflammatory conditions of the udder was revealed. Dr. Pierce is of opinion that nothing short of a similar periodical examination of milking cows in addition to the general examination for tuberculosis will safeguard the district against a similar occurrence in future, but we should like to point out that it must have been perfectly obvious to the person milking those cows that they were so suffering, and that the milk was of a character which should never have been sold. In such cases the person selling milk like that for food should be prosecuted. 